\title{
15
}

\section{Public policy theory, practice and skills: Advancing the debate}

\author{
John Wanna, Russell Ayres, Brian Head \\ and Trish Mercer
}

\begin{abstract}
Learning without thought is labour lost; thought without learning is perilous. (Confucius)

A theory must be tempered with reality. (Jawaharlal Nehru)

Circumstances give in reality to every political principle its distinguished colour and discriminating effect. (Edmund Burke)
\end{abstract}

\section{Debates around developing policy skills in government}

Debates about the need for developing better policy capacities and skills in government gained momentum in the 1950s and 1960s. At this time, there was a proliferation of interest in 'policy sciences' thinking and systemic approaches, popularised primarily by US scholars and 'pracademics'. Much of the policy theory-making emanating from the US was a legacy of the New Deal planning agendas of the mid-1930s and later strategic planning approaches developed by public and private organisations that helped to plan and strategise the war effort in the 1940s and the subsequent Cold War. Cognisant of calls for administrative reform 
in the public and private sectors (especially the Hoover Commission of 1949), large private corporations - such as the RAND Corporation, General Motors and other defence-related organisations that later inspired Robert McNamara's innovations under President Johnson (see Schick 1966, pp. 243-54)—promulgated a rationalist and systemic planning approach to policy sciences drawing on multidisciplinary expertise, including management and organisational planning, administrative science, economics, accounting, cost-benefit analysis, cybernetics and informational technologies.

From the 1960s onwards, the term 'policy' became identified as a professionalised set of analytical activities, which attracted several alternative theories and approaches. The previous overly rationalistic approaches extolling centralised planning were critiqued and amended but not entirely substituted (Dror 1968; Dye 1978). Other less rationalistic and more institutional approaches such as incrementalism were added, which acknowledged organisational behaviour, bounded rationalities, contingencies and opportunism. Policy was seen as an intentional set of activities that could be carefully designed and planned, studied intensively and professionally crafted through astuteness and prudence. Importantly, the principles and lessons could be taught or transmitted to practitioners working in real-life situations. Policy was seen as a mixture of actions, plans, promises, principles, motivations and desired intents, but, above all, it was guided by the practicalities of what was considered possible. Policy development, then, became a core function of government, and modern governments were urged to invest resources to enhance their policy capacities.

These intellectual developments around improving policy decisionmaking contributed an important 'supply-side factor' or 'push factor' to the growing international interest in the topic. Prior to that, of course, public servants had still contributed to 'policymaking', but generally described their work through a variety of other lenses, such as providing public financial resources, providing essential services, reviewing and drafting legislation, adopting technical improvements, setting community standards and enforcing regulatory arrangements. Significantly, in those days, the range of government responsibilities was relatively narrow (at least in the US) and closely linked to the provision of public good and market failure initiatives. 
The other influence to generate interest in policy skilling was the 'demand factor' emanating from governments themselves (and, to a certain extent, from pressure groups and the wider electorate interested in various policy ideas or frameworks). Demand for better policymaking and policy skills became a significant 'pull factor'. Postwar governments became increasingly committed to social change, the development of more extensive welfare states and improved living standards across the community (through amelioration policies and 'quality of life' concerns) (Castles 1998; Hogwood \& Gunn 1984; McEachern 1990). Policy goals and strategies signalled how governments wished to change living conditions and human behaviour-with policy programs the main means of effecting desired social change. Policy was often seen as a purposeful endeavour, with a focus on clarifying proposed or desired changes and planning their delivery more systematically. Policy was an organising concept that could span widely or narrowly depending on priorities and policy choices, but was also dependent on circumstances (as the third epigram above from Edmund Burke reminds us).

Given this historical background, what are the current and emerging debates around developing policy skills in government agencies? Three main topic areas may be distinguished. First, there has been concern over the levels of policy capacity a government might display or wish to achieve. For instance, capacities may be strong or weak, declining or improving, reactive or anticipatory, or there may be capacities for policy analysis or implementation. ${ }^{1}$ Second, there has been much written on the types of desired policy skills that may be needed, especially prospectively. This can include the range and mix of professional disciplinary expertise that may be required, as well as analytical and operational skills such as systems thinking, project management and 'life cycle' management for asset stewardship (see, for example, Adams et al. 2015). Third, there is considerable interest in how policy skills are transmitted and learnt, and what is the best way to address shortcomings and to prepare for new demands and emerging situations. Debates also focus on the degree to

\footnotetext{
1 In recent times, many governments have attempted to assess their relative capacities through formal assessment reviews with initiatives such as 'capability reviews'. These formal reviews began in the mid-2000s in the UK across departments and in the US, Canada and the Netherlands in relation to defence readiness. These ideas spread around 2010 to other nations such as Australia, New Zealand and Singapore. Some research/think tank institutes helped promote the idea and develop alternative methodologies, for instance the Institute for Government in the UK (see Panchamia \& Thomas n.d.). However, in some jurisdictions the commitment to sustaining capability reviews waned after the initial enthusiasm.
} 
which academic theories percolate into the thinking and practices of public servants or whether practical experience feeds into broader intellectual thinking on the topic. A commitment to policy skills development represents an investment in future capacities and capabilities including an anticipatory preparedness for new eventualities and aspirations. These topics are crucial aspects of any custodial 'stewardship' practised by government agencies and policy advisers.

A stewardship approach implies that decision-makers and participants in public policy take responsibility not only for developing the current skills, capabilities and productivity of their organisations and staff, but also for future capabilities (Makhlouf 2017; Moon et al. 2017). For instance, key considerations might include how to broaden the skills mix of an organisation; how to identify and invest in new skills and capabilities; how to develop analytical and critical thinking skills that have longerterm benefits; and how to enhance evaluative capabilities, which can potentially have a positive influence on the quality of decision-making, policy adaptation and operational performance.

At various times, the investment in new ways of thinking about policy may appear less important: a second-order priority or peripheral concern, outweighed by the exigencies of immediate demands confronting an organisation. Dealing with present-day expediencies will generally outweigh investments in future capabilities, which might be unknown or subject to much volatility or revision. Academic treatises may sit on shelves, perhaps only read by a handful of scholarly colleagues, critics or protégés. Nevertheless, as John Maynard Keynes (1936, p. 383) once observed, 'practical men who believe themselves quite exempt from any intellectual influence, are usually the slaves to some defunct economist ... [or] some academic scribbler of a few years back'. Keynes added that it took time for new ideas and theories to percolate 'so that the ideas which civil servants and politicians and even agitators apply to current events are not likely to be the newest' (p. 383).

One of the effects of the rise of professions is the tendency for every profession to have its own concomitant body of discrete theory about itself. The professions involved in public policy or public administration are no different. It is difficult to imagine that any profession would not develop a 'shadow' body of theory among its members most likely spreading into the world of intellectuals and professional academics. As discussed in Chapter 1, in Australia the adoption and development of a competency- 
based 'professions model' (along the lines of the UK government for its civil service) was recommended by the Independent review of the APS in 2019 (Department of the Prime Minister and Cabinet 2019) and accepted by the Morrison government, and is a further indication of investment in this important direction.

Many practitioners may work in relatively close alignment with policy theory models without fully appreciating the scholarly antecedents of their approach, and perhaps recognising the limitations of these models. For instance, many happily work with strategic planning norms, or follow incrementalist paths of development, or use project and risk management techniques, all of which are founded upon a body of theory. However, what is lost or neglected in uncritically applying a single model is the possibility of having a range of options available for government, various public authorities charged with policy responsibilities and parliament itself as the ultimate arbiter. Policy capabilities and approaches informed by policy theories constitute a professional toolkit of available means to achieve desired ends (see Mercer this volume, Chapter 3). Many public service training/professional development programs are at least partly based on one theoretical framework or another. A command of such knowledge helps to lift the sights of practitioners beyond the here and now. ${ }^{2}$

\section{To whom are these debates important?}

Understandably, policy practitioners (inside and outside government) are the main targets and intended recipients of policy theory. For existing or intending public servants, the development of policy skills is a vital component of their professional practice and of developing a 'community of practice' to deepen professional competencies and professional pride in the services performed (Hughes 1998). While practitioners are generally the intended market of 'academic scribblers', they can often be quite hard to reach or enthuse.

2 One characteristic that may have distinguished the more successful early responses to the COVID-19 pandemic (at least in the West) is the presence of an administrative class that has a reasonably deep understanding of the capabilities and roles of government, and the capacity to deploy those capabilities in an emergency. 
Departmental executives and line managers have long complained about the lack of policy capabilities of staff, and the lack of analytical skills or the ability to think outside the box (see Chapter 1 this volume; see also Peters 1996; Tiernan 2011). While their concerns are subjective impressions, their perspectives are generally accumulated from decades of experience and are often widely shared by colleagues. Many executives adopting a stewardship perspective have long argued for the need for formalised training programs to teach policymaking and improve the analytical capacities of the next generations of public service leaders (Moran 2017; Podger 2019).

Further down the public service hierarchies or at line manager levels, officials often initiate their own training, mostly through attending university courses and various forms of professional training and accreditation. Often such attendance in educational institutions is workrelated studying, but not necessarily in fields developing knowledge of policy theory or policy application per se. More tailored introductions to policy approaches are often delivered by public service commissions, specialist training institutes or via consultants in executive development courses (see Di Francesco 2015; Stewart 1999; Vromen \& Hurley 2015).

Nevertheless, the debates about the quality and development of policy skills in government are not restricted solely to policymakers in public sector employment. Academics and other public commentators have frequently joined this debate, often criticising perceived shortcomings in governmental decision-making and highlighting suboptimal examples of poor policy development. There is a rich literature on policy fiascos and policy failure written with the benefit of hindsight, but far less on successful policy outcomes (but see Luetjens, Mintrom \& 't Hart 2019). Many critics blame management fads in government for the supposed deterioration of policy capacity, displaced by the preoccupation with instrumentality and process-driven concerns (Ferguson 2019). The principal culprits are often cited as the preoccupation with new public management and the resort to outsourcing and contracting out (Boston 1995; Considine \& Painter 1997).

So, who else ought to find these debates to be of some importance? There are many audiences who could benefit from a better understanding of policy processes, how government decisions that affect them are made, and the potentialities and limitations of traditional government decision-making. As the processes of government policymaking become more porous and 
collaborative we might want to broaden the circle of stakeholders to whom policy theory is relevant. These interested stakeholders will include researchers, major interest groups and peak industry bodies, non-public sector operatives especially in the not-for-profit and charities sectors, as well as consultants, lobbyists, ministerial staffers, media commentators, political party operatives and interested members of the public anxious to improve their understanding of policy.

\section{What are the important contours of the debates?}

As many contributors to this volume attest, much of the debate about the relevance of policy theory and policy approaches generally concerns the existence of 'two world orders of discrete practice': academics and practitioners who operate seemingly as ships passing in the night. As a number of contributors also point out (see e.g. Threlfall \& Althaus this volume, Chapter 2; McConnell this volume, Chapter 14), this is a largely sterile and limiting controversy because the 'two worlds' may be differentially interconnecting -indeed, contributing to a volume such as this implies a recognition of the connection. There is ample evidence that policymakers in different fields of work form frames of reference informed by methods, tried and tested processes, analytical skills, design thinking, systems thinking and, to some extent, policymaking frameworks even if inchoate (Gill \& Colebatch 2006). Having said that, there is also considerable scope to assess the practical relevance and utility of specific policy theories or rival approaches.

The normative crux of the debates tends to be how applicable academic policy theories are to practitioners in the field in offering theory-informed advice for practice. There is a school of thought that academic theories are relevant to practitioners, even if practitioners have not directly experienced them, due to the percolation of ideas over time. Institutions in particular may hold to more rationalist policy concepts such as the classic policy cycle, as Mercer and Maurer discuss in this volume (see Chapters 3 and 12, respectively). Others question whether 'one theory' or 'one policy model' is applicable or sufficient in itself or whether some range of theories might be useful in different contexts (see Cairney this volume, Chapter 13). 
Hence, an important contour in the debates concerns whether a single theory is most relevant to inform practice or whether practitioners can selectively draw on a mix of concepts ('mix-and-match' or 'horses for courses') depending on circumstances. Some areas of policy are complex and rapidly changing while others are fairly stable and predictable; different theories may be appropriately applied to different contexts. Certainly, Cairney suggests that there is no perfect solution to any problem, and that we should 'synthesise the insights' from different approaches, taking care not to accept at face value claims that a simplified model is adequate to understanding or guiding action in the real world. Equally, care should be exercised in combining multiple theoretical insights, given, for instance, that the same terms can mean different things in different theoretical contexts, and the lack of agreement as to how they can/should be combined. One approach might be to employ multiple theories to provide complementary perspectives on the same event (Cairney 2019, pp. 236-8). Within this volume, contributors have explored or employed theoretical approaches ranging across the spectrum from a rationalist focus on centralised decision-making to multiple actors operating within a complex process, and, in some instances (see Chapters 8 and 11, by Ayres and Gilding, respectively), have combined more than one theoretical approach to aid their policy analysis.

\section{What range of policy skills are we talking about?}

Much academic discussion in this domain necessarily takes place at a high level of abstraction, involving stylised models, policy cycles and frameworks, comprehensive planning methods and project management techniques. In practice, many policy professionals are engaged in deeply pragmatic ways in very specific areas of policymaking or seeking to solve discrete policy problems. Overly generic models or theories may be of limited relevance to such practitioners and circumstances, and could impede action where it is needed to respond to an urgent need or there is a political imperative to act. There are also well-recognised cognitive limitations inherent in theory-making. As McConnell (this volume, Chapter 14) writes: 
In policy studies, there is no 'theory of everything' that would be able to capture the circumstances and variables of every scenario, accompanied by a definitive statement on causal factors and a prediction of what might happen in any particular situation.

He advises that well-informed practitioners can take the insights from academic theories in 'deep or light ways — as they see fit'. As for academics, they may be well advised to get closer to the 'coalface' of government decision-making and action, not only to gain insights for their own research, but also to find ways to bring their insights to bear in helping practitioners seeking to improve their decision-making, to better use methods and techniques, and to understand the risks and downsides of suboptimal outcomes.

This discussion also raises the issue of whether there are distinct policy skills that are sui generis to different policy fields, and whether using abstract, generic theory to inform practice may require much greater differentiation of the work of policy itself. Governments have a wide and ever-changing set of responsibilities, mandates and policy purviews; their officials and organisations are managing many different functions, activities, processes and business practices, using different policy levers or policy tools, and with different levels of resources and imperatives (Peters 1996). Government is not singular or uniform, nor are the possibilities of policymaking evenly spread across its various functions and organisations, with specialist areas tending to focus on the subject matter of their policy focus, such as the economy, the environment, global security or industry sectors. ${ }^{3}$

3 A few examples will serve to illustrate this point:

- an official in Finance or Treasury working on public finances or macroeconomic focused on a highly specialised policy space, with its own parameters and specific concerns-generic policy theories may be of little use in their day-to-day calculations (on the other hand, these officials may be 'captured' by prevailing orthodoxies and fail to countenance the bigger policy picture or political realities).

- ministers insisting on a particular course of action (e.g. stimulus spending, fiscal consolidation and a return to budgetary surpluses, or a pay-down of debt levels) will also constrain policy options, overriding any policy model or theory that might otherwise seem relevant.

- public servants concerned with matters dominated by scientific or technological challenges tend to focus on scientific calculations and advice, and may be relatively naive about the realpolitik of policy.

- policymakers in regulatory functions or in areas of compliance or taxation may not see policy models about how policy is made as relevant to the complex issues for which they are responsible and legally accountable; rather, their focus may be on regulatory augmentation, parameter adjustments, compliance strategies and operating under changing legal interpretations and determinations. 
Notwithstanding the role of specialist capacities and approaches, most practitioners will have some involvement in policy adjustment or development, and some policy theories will provide them with a better handle on making these decisions and taking actions. At a fundamental level, all forms of understanding, all analytical and communication skills, are crucial aspects of a practitioner's conceptualisation of the policy process. They may not express such interpretations in terms of theories, models or approaches but they inform their practice and the sense-making abilities of government policy, even while their articulated concerns may be more about methods of decision-making, authorisations to proceed, risk assessments, things that might go wrong or the unintended consequences of whatever action might be deemed appropriate.

\section{The contributions of this volume}

The successful workshop in 2018, on which this volume is based, began with the premise that the relationships between policy theory and actual practice were far from straightforward and linear. It was recognised from the outset that the relationships were complicated and sometimes combative in many areas of public policymaking. It was often recounted that theoreticians felt frustrated that their insights seemed not to be valued or widely applied by practitioners (and, if they were applied, that their theoretical insights were not generally acknowledged). Further, it was alleged that many practitioners, if they were aware of policy theory, found the products of the academy impracticable, whatever their intellectual and analytical merits. We were aware that these views were an article of faith for many observers and had become the stereotypical view of the relationship between these 'two worlds'. However, we were also motivated to search for the spaces of intersection between theory and practice, and for better ways of bridging the 'two worlds'.

This volume goes well beyond the defence of a particular model or theory, or the 'war stories' that practitioners routinely recount to defend a view that no model captures the chaos and complexity of practice. The contributions to this volume show that the reality of what practitioners rely on to make decisions is much more complex than the stereotype would have us believe. Often when we delve into frontline policy work, experience may sometimes be worse than the stereotype suggests, but also, in places, perhaps better than we might expect. Certainly the picture that 
emerges here is that the range of experiences and the perceptions across the divide between theory and practice are many and varied, and resist simple classification or summary. This complexity is reinforced in this volume in chapters by David Threlfall and Catherine Althaus (Chapter 2) and also Karl Löfgren and Sarah Hendrica Bickerton (Chapter 5). Allan McConnell reminds us that we should 'beware of over-amplifying the differences and stereotyping the separation' between these two worlds (Chapter 14). What emerges is the realisation that the trend to seek better knowledge of policy and information about alternative possibilities seems to be broadly headed in the right direction. There are now many theoreticians who either have personal experience of the practicalities of policymaking or are very open to understanding the perspectives of those who have had such experience. Meanwhile, there are also many practitioners who have immersed themselves in the literature and emerged considerably wiser, if not struck by a single and overwhelming bolt of enlightenment. In assessing the current state of affairs in the Australian context, they are well represented in this monograph. To many practitioners, the glass may seem only half full, yet there is every prospect that it may become fuller.

It is true that a number of the contributions to this book stress that the tasks of applying policy theory to practice are fraught and difficult to achieve for a variety of reasons, and that it can be hard to trace the influences when they do occur (see also Colebatch 2010; Parsons 2004; Wanna 2015). Examples include Kathleen Mackie's exploration of succeeding and failing in crafting environmental policy, and, at a deeper philosophical and cultural level, Craig Ritchie's critique of the Western Enlightenment assumptions underpinning the contemporary policy enterprise (Chapters 9 and 10, respectively). In her fieldwork into policymaking in the Commonwealth's Environment department, Mackie found her interviewees rarely drew on policy theory to inform their policy work; even experienced and adept policy officers 'struggled to define "policy"; they considered policy work instinctual—it was in their DNA' (Chapter 9).

Val Barrett, in her review of the attitudes to public management in complex and hard to 'steer' institutions like the Australian and British parliaments (Chapter 6), concludes that the differences between parliament and other public institutions are not as great as parliamentary practitioners might imagine, and that the contemporary public management theories they tend to shun could be very relevant for strategic reform initiatives. 
In particular, she argues that the public value approach and associated paradigms 'lend themselves as well to parliamentary administration as to public administration'.

Contrasting with and leavening this picture, are chapters by Russell Ayres (Chapter 8), Meredith Edwards (Chapter 7), Louise Gilding (Chapter 11), Andrew Maurer (Chapter 12) and Trish Mercer (Chapter 3). All demonstrate that theoretical work can resonate for individual public servants who find a framework (or frameworks) to draw on-one that 'strikes a chord' - to support them to understand real policy world issues and dilemmas. On the continuum between academics and practitioners, these contributions are generally of the blended, 'pracademic' sort. This practitioner-cum-academic is perhaps a type that would bear more study, just as the notion of the 'policy entrepreneur' has been a focus of discussion in recent decades, especially in North America where much more interaction and career exchanges between town and gown occurs.

Many contributors ask whether a more explicit understanding of the full range of policy frameworks would help policy workers to do their jobs better. Kathleen Mackie and Trish Mercer both pose such questions in their chapters. This is surely worth further exploration, given the ongoing angst expressed at the political and commentating level (discussed earlier) as to the policy capacity of the public services in Australia and other Westminster jurisdictions. This also reinforces the significance of understanding the breadth of the target group for such policy theory. This is not simply about breaking down the elitist hegemony of the so-called 'Canberra bubble' as many of our political leaders are fond of suggesting. Policy work is done at many levels across the public services, involving various stages of policy exposure, and various actors and stakeholders. Crucially, it involves many non-public sector policy advisers and influential operatives across the community and globally.

Overall, the contributions to this volume tend to suggest that policy theory needs to describe and engage with 'policy in action', an emphasis on the practical doing of policy work that resonates throughout the APS capability roadmap prepared for the APS Secretaries Board in March 2019 (Australian Government 2019) and discussed in Chapter 1. There are also chapters here that should give practitioners and those tasked with training and developing future practitioners serious pause for thought. John Wanna, for example, in Chapter 4, provides a constructive critique of the pedagogical challenges in offering senior executive education 
including in presenting relevant theories in such a teaching and learning setting. As discussed earlier, Paul Cairney in Chapter 13 and elsewhere (2019) makes some strong and clear-eyed observations about how some practitioners risk uncritical or inappropriate application of superficially attractive models if they do not explore, understand and adapt to the underlying assumptions and preferences of those models.

\section{Future directions}

We know comparatively little about what participants are offered in formal public policy teaching, other than perhaps the core offerings in the Australia and New Zealand School of Government (ANZSOG) programs, and even less about how those students with policy experience respond to this. Following Di Francesco's comprehensive survey of tertiary institutions teaching policy studies (2015), we could extend his analysis to discover what is actually taught under the banner of public policy theory. Di Francesco discusses at a general level the types of courses and subject matter taught across tertiary institutions (i.e. key components of policy analysis instruction), but, perhaps of necessity, does not delve into the coverage of theories or particular approaches, although he does produce typologies based on course titles offered.

But, as well as enhancing our understanding of specific policy theories within formal tertiary training, there is, as Cairney suggests, value in undertaking interactive discussions with current public servants to communicate the complexity of policy and distil the insights from the diverse range of policy theory (Cairney 2015, p. 33). Academics are often not clear as to how practitioners can deploy theory. Beyond the suggestions made earlier in this conclusion, one means of offering practical lessons to time-poor practitioners could be in the form of 'policy theorybites'-short training sessions aimed at conveying useful policy concepts (sometimes embedded within a policy framework), such as:

- how better to undertake policy 'on the run', which tends to be produced during 'issue attention cycles' associated with relentless media attention

- the importance of always being ready for a 'policy window' to open

- the insights into 'fast policy thinking', which can be gleaned from behavioural economics and psychology studies 
- how to develop reflexive capacities and encourage curiosity and inquiry

- appreciating the value of policy evaluation and making desired outcomes and impacts transparent and measurable

- exploring what makes a problem seem 'wicked' and what range of interrelated initiatives are appropriate for such multidimensional problems

- how to work comfortably in the 'purple zone', which can create tensions between public servants and ministers (see Alford et al. 2017; Alford \& Head 2017; Althaus, Bridgman \& Davis 2018; Cairney \& Weible 2017; Kingdon 2011).

There have been frequent calls, as Threlfall and Althaus remind us in Chapter 2, to shed more light on the broader area of how theory can be tested against practice. Both Gilding and Maurer (this volume, Chapters 11 and 12, respectively) provide rare insights into this area. Mackie (see Chapter 9) has highlighted the significance of the agency exercised by policy officials within environmental policymaking as a key driver in the success or failure of specific policies and programs; this is an area that warrants more attention in theory, notwithstanding the difficulties in accessing the insider world of public servants to understand their capacity to act as 'policy agents' within a Westminster system. A further challenge for us is: can we move beyond the individual case studies that only explore this link in specific contexts? Paul 't Hart and colleagues, using an adapted policy success assessment framework by McConnell, have recently compiled a series of international studies on learning from policy success, including a volume on Australia and New Zealand (see Luetjens, Mintrom \& 't Hart 2019). While most of their illustrative cases are long-term policy trajectories, there are many valuable lessons in such comparative assessments.

We might wish to encourage the practice of preparing 'learning briefs'written heuristically to disseminate specific learnings and good practices across agencies. ${ }^{4}$ Some Commonwealth departments require middle and senior staff engaged in successful policy work to prepare and disseminate learning briefs that capture practical learnings for colleagues to consider. It could be instructive, perhaps through a practitioner-academic partnership,

4 In some government departments these written 'learning briefs' already exist but are internal documents and not made public or widely disseminated across government. Many of these would make valuable case studies to wider audiences even if some critical reflections may be divulged. 
to examine whether embedding a theoretical framework into such briefs might enhance the insights to be garnered: for instance, running the ruler of McConnell's assessment framework over the particular policy outcomes, or employing the multiple streams approach to investigate the role of ideas and entrepreneurial policy actors in agenda-setting. This would complement, and potentially reach a wider audience, than the 'action-learning' teaching cases such as those employing public value as a prism for diagnosis produced by ANZSOG and other training institutes. We can augment these efforts with pracademic podcasts, policy 'bites', policy 'windows' and more use of visualisation approaches to summarise complex concepts and processes (e.g. flow charts and concept maps).

Whatever the specifics, there is a considerable body of applied research that could profitably be done to advance our understanding of the value of policy theory to develop policy skills. In particular, partnerships could be formed between academics and practitioners to explore how various policy theories are actually used, both in the workplace and as a language for communicating shared concepts and approaches. For instance, while scholars have raised the issue of public value encouraging bureaucrats to exercise spontaneous agency, we still have little direct evidence to discover the extent to which this may help to explain the strong appeal this approach holds for senior public servants in Westminster systems, particularly in Australia and New Zealand. As the exponents of public value theory have themselves been quick to recognise, this empirical research agenda as yet lacks grounding in rigorous studies. A much needed research agenda:

Could test empirically whether the tools of public value truly have an impact on the thoughts and actions of public managers, or is this simply a conceit of public management teachers. (Hartley et al. 2017, pp. 671, 680-1)

Within this applied research agenda, we might wish to conduct significant studies to examine whether, how and to what effect policy frameworks, models or theories offered through graduate and postgraduate study or training courses are influencing and being applied by policy practitioners working in the intergovernmental space, encompassing both Commonwealth and state public servants in Australia and across central and line agencies, policy developers and implementers, both metropolitan and regional. A partnership between ANZSOG and a university with a dedicated public policy school would be an ideal platform to develop this research proposal in consultation with key public service agencies. 
Attempting all of these areas of applied research may be ambitious, perhaps overly so-yet, to shed light on the interaction or not between theory and practice, it is essential. Without such work being undertaken and published we will remain largely in the dark about how the 'two worlds' connect and influence each other, and how each might work with the other to improve the crucial work of government and policymaking.

\section{A concluding comment}

As a field of scholarly research and theoretical interest, public policy is avowedly multidisciplinary and interdisciplinary. As this book amply demonstrates, it is also concerned with reaching across the divide that inevitably lies between theory and practice. These are among the strengths of the applied field of study, although they do undoubtedly raise challenges, too. Where, perhaps, there remains the most work to be done-if the contributions in this book are a guide - is in deepening our understanding of what actually happens when policy is developed and deployed, and especially why it happens the way it does. What do practitioners think they are doing and why they are doing it? Is there a collective set of norms and expectations among public servants and the myriad others involved in generating policy advice, or is this an irredeemably heterogeneous group who engage in policy with differential values and behavioural practices? What changes if we shift our focus from specific, individual cases or actions and try to understand what is happening at a broader and more systemic level? If these difficult-to-answer empirical and analytical questions can in some measure be answered, then what do the answers mean, normatively? Is there a need to build a more coherent profession of policymakers, analysts and advisers and encourage the development of communities of practice? If so, what would be the core characteristics of such a profession? What would it 'profess' and what would its value be to our polity and to the wider community? These are, of course, questions that this publication certainly does not fully answer, but it does, we hope, make clear the need to seek some answers along these lines, even as the Australian policy enterprise continues to grapple with major policy challenges (demonstrated most recently by the COVID-19 pandemic). 


\section{References}

Adams, D, Colebatch, HK \& Walker, CK 2015, 'Learning about learning: Discovering the work of policy', Australian Journal of Public Administration, vol. 74, no. 2, pp. 101-11, doi.org/10.1111/1467-8500.12119.

Alford, J, Douglas, S, Geuijen, K \& 't Hart, P 2017, 'Ventures in public value management: Introduction to the symposium', Public Management Review, vol. 19, no. 5, pp. 589-604, doi.org/10.1080/14719037.2016.1192160.

Alford, J \& Head, BW 2017, 'Wicked and less wicked problems: A typology and a contingency framework', Policy and Society, vol. 36, no. 3, pp. 397-413, doi.org/10.1080/14494035.2017.1361634.

Althaus, C, Bridgman, P \& Davis, G 2018, The Australian policy handbook: A practical guide to the policy-making process, 6th edn, Allen \& Unwin, Sydney, NSW.

Boston, J 1995, 'Inherently governmental functions and the limits to contracting out', in J Boston (ed.), The state under contract, Bridget Williams Books, Wellington, NZ.

Cairney, P 2015, 'How can policy theory have an impact on policymaking? The role of theory-led academic-practitioner discussions', Teaching Public Administration, vol.33, no. 1,pp. 22-39, doi.org/10.1177/0144739414532284.

Cairney, P 2019, Understanding public policy theories and issues, 2nd edn, Red Globe Press, London.

Cairney, P \& Weible, C 2017, 'The new policy sciences', Policy Sciences, vol. 50, no. 4, pp. 619-27, doi.org/10.1007/s11077-017-9304-2.

Castles, F 1998, Comparative public policy: Patterns of post-war transformation, Edward Elgar, Cheltenham, UK.

Colebatch, H 2010, Policy, Open University Press, Maidenhead, UK.

Considine, M \& Painter, M (eds) 1997, Managerialism: The great debate. Melbourne University Press, Carlton, Vic.

Department of the Prime Minister and Cabinet (PM\&C) 2019, Our public service, our future. Independent review of the Australian Public Service, viewed 4 June 2018, www.apsreview.gov.au/about.

Di Francesco M 2015, 'Policy analysis instruction in Australia', in B Head \& K Crowley (eds), Policy analysis in Australia, Policy Press, Bristol, UK, doi.org/10.1332/policypress/9781447310273.003.0017. 
Dror, Y 1968, Public policy making re-examined, Chandler, San Francisco, LA.

Dye, TR 1978, Understanding public policy, Prentice-Hall, Englewood Cliffs, NJ.

Ferguson, B 2019, Competing for influence: The role of the public service in better government in Australia, ANU Press, Canberra, ACT, doi.org/10.22459/ CI.2019.

Gill, Z \& Colebatch H 2006, “'Busy little workers”: Policy workers' own accounts', in H Colebatch (ed.), Beyond the policy cycle, Allen \& Unwin, Sydney, NSW.

Hartley, J, Alford, J, Knies, E \& Douglas, S 2017, 'Towards an empirical research agenda for public value theory', Public Management Review, vol. 19, no. 5, pp. 670-85, doi.org/10.1080/14719037.2016.1192166.

Hogwood, B \& Gunn, L 1984, Policy analysis for the real world, Oxford University Press, Oxford, UK.

Hughes, P 1998, 'A spirit of service', Paterson Oration, ANZSOG, Melbourne.

Keynes, JM 1936, The general theory of employment, interest and money, Macmillan, London, UK.

Kingdon, J 2011, Agendas, alternatives and public policies, 2nd edn, Little Brown, Boston, MA.

Luetjens, J, Mintrom M \& 't Hart P 2019, Successful public policy: Lessons from Australia and New Zealand, ANU Press, Canberra, ACT, doi.org/10.22459/ SPP.2019.

Makhlouf, G 2017, 'The importance of stewardship for public sector productivity', Paper presented to the New Zealand Public Sector Finance Leadership Conference, Wellington.

McEachern, D 1990, The expanding state: Class and economy in Europe since 1945, Harvester Wheatsheaf, London, UK.

Moon, K, Marsh, D, Dickinson, H \& Carey, G 2017, Is all stewardship equal? Developing a typology of stewardship approaches, Public Service Research Group Issues Paper, no. 2, viewed 1 June 2020, www.unsw.adfa.edu.au/public-serviceresearch-group/sites/cpsr/files/uploads/Issues\%202\%20Stewardship.pdf.

Moran, T 2017, 'Back in the Game', IPAA Fellows' Oration, IPAA, Melbourne, 21 November.

Panchamia, N \& Thomas, P n.d., Capability reviews, Institute for Governance, viewed 2 June 2020, www.instituteforgovernment.org.uk/sites/default/files/ case $\% 20$ study\%20capabilities.pdf. 
Parsons, W 2004, Public policy, Edward Elgar, Aldershot, UK.

Peters, G 1996, The policy capacity of government, CCMD, Ottawa, Canada.

Podger, A 2019, 'Protecting and nurturing the role and capability of the Australian Public Service', Parliamentary Library Lecture, Canberra, 10 September.

Schick, A 1966, 'The road to PPB: The stages of budget reform', Public Administration Review, vol. 26, no. 4, pp. 243-58, doi.org/10.2307/973296.

Stewart, R 1999, Public policy: Strategy and accountability, Macmillan, Melbourne, Vic.

Tiernan, A 2011, 'Advising Australian federal governments: Assessing the evolving capacity and role of the public service', Australian Journal of Public Administration, vol. 70, no. 4, pp. 335-46, doi.org/10.1111/j.14678500.2011.00742.x.

Vromen, A \& Hurley, P 2015, 'Consultants, think tanks and public policy', in B Head \& K Crowley (eds), Policy analysis in Australia, Policy Press, Bristol, UK.

Wanna, J 2015, 'Policy analysis at the federal government level', in B Head \& K Crowley (eds), Policy analysis in Australia, Policy Press, Bristol, UK, doi.org/10.1332/policypress/9781447310273.003.0005. 
This text is taken from Learning Policy, Doing Policy: Interactions Between Public Policy Theory, Practice and Teaching, edited by Trish Mercer, Russell Ayres, Brian Head and John Wanna, published 2021 by ANU Press, The Australian National University, Canberra, Australia.

doi.org/10.22459/LPDP.2021.15 